\title{
Joya de Cerén. La dinámica sociocultural de una co- munidad semicampesina de El Salvador, de Carlos Benjamín Lara Martínez, Secretaría de Cultura de la Presidencia, Dirección de publicaciones e impresos, Colección Antropología e Historia, volumen 2, 2013, segunda edición, San Salvador, 226 pp., ISBN 978- 99923-0-234-7
}

\section{Luis Rodríguez}

Universidad Nacional Autónoma de México, Instituto de Investigaciones Antropológicas, Programa de Investigaciones Multidisciplinarias sobre Mesoamérica y el Sureste lurodri@unam.mx

Dr. Luis Rodríguez es investigador ordinario de carrera, titular «A», de tiempo completo, con definitividad de la Universidad Nacional Autónoma de México. Es miembro del Sistema Nacional de Investigadores (SNI), Nivel I. Desde septiembre 2011 es editor de la Revista Pueblos y fronteras digital del PROIMMSE-IIA, UNAM. Actualmente desarrolla el programa de investigación «Acción pública y desarrollo social en el sureste de México y Centroamérica». Sus temas de interés son: Teoría Antropológica, Antropología Política, Políticas públicas, Gestión local y el proceso de la formación cotidiana del Estado. Últimas publicaciones: «Inasistencia escolar, gobierno local y política social: un análisis de marcos», en el libro Politicas sociales en Iberoamérica. Entre la precariedad social y el cambio político, Red Iberoamericana para el Estudio de Políticas Sociales (2013) y en coautoría con Xochitl Leyva «Disputed spaces and clientelistics networks in the formation of the municipality of Maravilla Tenejapa», en Remunicipalization in Chiapas. Politics and the political in times of counter-insurgency, CIESAS y International Work Group for Indigenous Affairs (IWGIA) (2012).

Cuadernos de Antropología 2014, 24(1): 89-96

Recibido: 16-12-2013 / Aceptado: 21-06-2014

Revista del Laboratorio de Etnología María Eugenia Bozzoli Vargas Escuela de Antropología, Universidad de Costa Rica http://revistas.ucr.ac.cr/index.php/antropologia ISSN 2215-356X 
Plantear viejas preguntas parece a menudo tan inútil como las viejas respuestas que le acompañan. La pregunta ¿qué es una comunidad? trae a la mente, para muchos de nosotros, un tipo particular del viejo argumento cuasi evolucionista que va desde la clásica división entre "gemenschaft" y "gesellschaft" de Ferdinand Tönnies como origen del debate en la Sociología a la oposición folk-urbano de la etnología de Robert Redfield (año) y Alfonso Villa Rojas en la Antropología, hasta las frases gastadas de un programa político para las revoluciones del siglo XXI. Sin embargo, en la Latinoamérica contemporánea, muchas de las preguntas que más radicalmente atraen a la imaginación etnográfica y afectan a nuestras sociedades son cuestiones que tienen que ver, claramente, con las dinámicas socioculturales locales y comunitarias.

En torno a estas cuestiones, debemos estar agradecidos con la Secretaría de Cultura de la Presidencia, la cual, a través de la Dirección de Publicaciones e Impresos, ha realizado la valiente decisión, en el actual contexto de crisis, de realizar la segunda edición de Joya de Cerén. La dinámica sociocultural de una comunidad semicampesina de El Salvador de Carlos Benjamín Lara Martínez (2013). Una obra que se presenta con el objetivo, según Lara (2013), de "proporcionar una visión de la dinámica sociocultural global de esta comunidad, con el objeto de que este estudio sirva de base para impulsar proyectos de desarrollo cultural" y que nos da la oportunidad de ver otra vez aquella pregunta general de añoso trillado en la Antropología, “¿qué es una comunidad?”, en nuestros propios espacios y plazos inmediatos preñados, hoy, por eso que llaman "globalización” o "planetarización”.

Señalo esto porque a pesar de los cambios desde 1995, cuando se realizó el trabajo de campo de la investigación de la que da cuenta el libro, el diagnóstico oportuno en relación, de acuerdo con Lara (2013) con que "carecemos de un conocimiento preciso sobre el funcionamiento de una comunidad rural en tanto que totalidad social" mantiene una resonancia de apabullante vigencia. Aunado a que la idea de "comunidad" es, en cualquier contexto, difícil de usar debido a la polisemia del término y porque muchos de los sentidos principales de la categoría se anclan en la presuposición de un conjunto de interacciones cara a cara, relaciones primordiales, que son armónicas y la vida simple de grupos arcaicos, primitivos, tradicionales; frente a la complejidad del mundo urbano y la modernidad. Y no es una cuestión aquí de elegir o definir algún sentido moralmente correcto de esta categoría, sino simplemente de reconocer que, por desgracia, los depósitos emotivos en la palabra suman elementos de la gran complejidad teórica e histórica que entraña el concepto.

En 226 páginas de las que consta el libro, divididas en los prolegómenos y siete capítulos, Carlos Benjamín Lara Martínez afronta este importante reto antropológico. Siguiendo los cánones de las buenas etnografías clásicas y quizás hasta con cierto dejo de visión palermiana del asunto, el capítulo I “Características Generales" presenta un buen recorrido en relación con las bases materiales de la cultura. Tierras planas formadas por sedimentación de cenizas y materiales volcánicos, irrigadas por diversos ríos que proporcionan humedad y nutren una vegetación abundante de bosque húmedo subtropical. 
Esos aspectos del medio ambiente le permiten al lector ubicar la zona en la donde se realiza el estudio, el cantón Joya de Cerén del municipio de San Juan de Opico, departamento de La Libertad; para adentrarse en los paisajes sociales de la localidad de estudio. Tierras fértiles donde se asentaron haciendas y la población explotaba la caña de azúcar. Una colonia con, según el autor citado, ordenamiento urbanístico que es producto de la acción planificada que los ingenieros del Instituto de Colonización Rural realizaron en los años 50 y cuatro caseríos periféricos: Plan del Hoyo, La Ranchería, Estación Bandera (parte) y Agua Zarca. Así, se comprende el presente etnográfico desde el cual se realiza la descripción y análisis presentados en los subsecuentes capítulos.

En el segundo acápite "La historia del cantón”, el autor revisa los fenómenos de mayor trascendencia para la historia del cantón Joya de Cerén desde la época prehispánica al presente etnográfico. Constata la construcción de diferentes sistemas sociales en las diversas etapas históricas generales (época prehispánica, época colonial, etc.) y del proceso de construcción de la nación salvadoreña (los proyectos del Estado que tuvieron algunos efectos sobre el cantón en los siglos XIX y XX). Con ello, destaco que Lara (2013) identifica en el amplio lienzo de la historia tanto los puntos de ruptura como los procesos que mantienen una línea de continuidad; sobre estos últimos, a las instituciones sociales las cuales son fundamento de su explicación de la comunidad semicampesina:

En primer lugar, la presencia constante de una agricultura de subsistencia basada en la producción de granos básicos a pequeña escala [... que] ha coexistido, con mayor o menor fuerza, con una economía comercial y, más recientemente, empresarial [... y] El segundo proceso es la estructuración de la comunidad a partir de la organización de los grupos domésticos (Lara, 2013, p. 54).

El primero se realiza sobre la base de la propiedad privada de la tierra, a pesar de la intervención estatal representada por el Instituto de Colonización Rural (ICR) que en 1954 impulsó la propiedad colectiva. En efecto, nos enteramos que "el 4 de septiembre de 1954 el ICR repartió las primeras 80 viviendas, con lo cual dio inicio la organización de la colonia Joya de Cerén” (Lara, 2013, p. 44). Desde luego, el proyecto no solucionó el "problema agrario en el país" y bajo las valoraciones de los beneficiarios, estos optaron por regresar al régimen de propiedad privada. Sobre este tópico, el autor mencionado anteriormente presenta una interesante historia sobre prácticas y concepciones de la corrupción en la que participan, además de los pobladores locales y las agencias del Estado, la Cooperación Internacional; pero sobre la que no doy más detalles para ir despertando la curiosidad e invitar a la lectura integra de este libro.

De no menor interés es lo presentado en el capítulo III "Economía”, en el cual aborda la base económica de la reproducción en Joya de Cerén y nos explica a mayor detalle qué entiende por "economía de subsistencia", en donde intuyo una orientación teórica “centrada en el actor". Me explico, Lara se aleja -sin 
desconocerlas- de las explicaciones de carácter estructural o de asentar que dadas las "condiciones objetivas" de la economía nacional, las formas de reproducción económica en Joya de Cerén no podrían ser de otra forma, para argumentar de manera convincente que se trata de una "actitud del productor de trabajar con el objetivo de obtener lo necesario para garantizar la subsistencia de su grupo familiar" (Lara, 2013, p. 78). Para lograrlo, los habitantes de Joya de Cerén optan por mantener su agricultura de subsistencia y contratarse eventualmente en el trabajo asalariado. Adoptar esta lógica es lo que denomina como semicampesino.

Este capítulo llama mi atención, ya que enfrenta a una de las principales antinomias de la teoría marxista de los sesentas y setentas de la antropología mundial. Me refiero al debate campesinista-descampesinista, cuya preocupación central se encontraba en dilucidar los medios materiales que permiten a los grupos campesinos su reproducción y si estos tendrían un carácter de clase social. Por un lado, los descampesinistas eran encabezados en México por Roger Bartra y defendían la tesis que en la teoría marxista no había una teoría del campesinado, sino sobre su desaparición. Por la otra corriente, los campesinistas, encabezados por Palerm, aseveraban la existencia del "modo de producción campesino" que se presenta porque los campesinos habían generado formas de adaptación al sistema capitalista para mantener el control sobre la tierra, cierto grado de control sobre su fuerza de trabajo y algunas ventajas en su forma de producción en el contexto de explotación capitalista; es decir, el modo de producción campesino solo es posible en su articulación con el modo de producción capitalista.

El genio de Lara (2013) es acuñar una categoría conceptual que permite aglutinar las características antes descritas y, lejos de esos debates que tenían tras de sí, la incógnita sobre las posibilidades del campesinado en convertirse en clase social y, por lo tanto, parte de las fuerzas dinamizadoras de las contradicciones del sistema capitalista. En su lugar, se marca la influencia de Wolf, en el sentido de documentar la "estrategia campesina" de sobrevivencia y su conflictiva relación con el trabajo asalariado a fin de preservar tiempo, esfuerzos y recursos al desarrollo de relaciones sociales en su comunidad.

El capítulo III y el cuarto acápite "La dinámica de los grupos domésticos" son los que me parecen centrales en los propósitos ya señalados, pues, es en este último en donde desarrolla su análisis al segundo hilo extraído del lienzo de la historia desde el segundo capítulo "La dinámica de los grupos domésticos ". Aquí sigue las reflexiones de antropólogos tales como Alfonso Villa Rojas, Lourdes Arizpe, Jack Goody, Payson Sheets, Mounsey Taggart, entre otros, para afirmar que además de la residencia y el consumo, los grupos domésticos cumplen con la función de organizar "las relaciones solidaridad y ayuda mutua [... ahí] se transmiten las, normas y valores culturales que orientan la vida social de sus miembros" (Lara, 2013, p. 103). Y eleva el postulado a un alto nivel de generalidad explicativa al considerar que lo descubierto en Joya de Cerén se trata de un caso etnográfico ejemplar del modelo mesoamericano del grupo doméstico semicampesino. 
Tal como en otras ocasiones, he dialogado con el autor, y en ello hemos coincidido, necesitamos desarrollar más investigación etnográfica sobre los grupos domésticos y no solo desde el presente etnográfico, sino en una perspectiva diacrónica y en diferentes latitudes de Mesoamérica; para darle mayor consistencia a esta generalización teorética; empero, este es un programa de investigación que esperara a mejores tiempos, etnógrafos y etnógrafas para su desarrollo. En esta labor, el libro Joya de Cerén. La dinámica sociocultural de una comunidad semicampesina de El Salvador, de Carlos Benjamín Lara Martínez (2013) será sin duda alguna una invaluable guía.

Pues, bien, desde la perspectiva marxista, las relaciones de dominación son una concomitante de las relaciones de producción; es decir, los capitalistas ricos, mantienen en relación de subordinación a los campesinos pobres; por lo que el control político corporativo sobre las "masas campesinas" era el resultado de las necesidades de la reproducción del capital. Una excelente salida a ese nivel de generalización teórica la presenta el escritor en el capítulo V "La confrontación política" donde se adentra al ámbito de la política local.

Con lo mejor del instrumental teórico de la escuela procesualista de la antropología social; es decir, la identificación de agentes sociales a nivel local, sus funciones, posiciones y relaciones, ya sea de complementariedad, de oposición, concomitancia o de resistencia, nos habla de un complejo mundo político local que se mueve en los entretelones de la disputa por el control sobre recursos significativos y escasos; además de la descripción de las dinámicas y razones de las demandas propias de relativa autonomía en relación con el control de recursos en la propia localidad frente a las instituciones gubernamentales.

Gracias a esa perspectiva, Lara (2013) se aleja de presentarnos una maniquea división entre pobres y ricos, dominadores y dominados, y nos invita a reconocer la diferenciación política interna de las comunidades campesinas y la complejidad del mundo político local, donde los agentes tienen las oportunidades de variar sus posiciones según las diferentes organizaciones y recursos a los que tienen acceso; así como por el prestigio acumulado por su defensa y adscripción a los valores locales. Así, documenta cómo los grupos domésticos que optaron por diferentes proyectos productivos - propiedad privada vs. cooperativa- encuentran su expresión política en la constitución de dos Asociaciones de Desarrollo Comunitario (Adesco), las cuales con sus vínculos con otros agentes - como los partidos políticos- compiten por "controlar los recursos de la comunidad y los proyectos que se impulsan en el cantón” (Lara, 2013, p. 105) para lograr ganar posiciones en la estructura política local.

Aquí solo señalaría mi desacuerdo con el uso que hace de la categoría de geopolítica, cuya única utilidad analítica es la distinción entre los "sujetos sociales internos; y aquellos que no pertenecen al cantón, sujetos sociales externos" (Lara 2013, p. 105). Al ser una categoría proveniente de la ciencia política y en particular aplicable a los estudios internacionales, debemos ser claros del contenido del concepto; el cual 
refiere a la ofensiva por la soberanía entre dos entidades políticas; pero que el estudio de caso -ampliación del servicio de agua- documenta la disputa por mayor autonomía entre diferentes niveles de integración sociocultural (grupos domésticos, las Adesco, otras asociaciones locales) en concierto con los niveles de articulación sociocultural (la municipalidad, el Estado, la cooperación internacional); es decir, entidades que compiten por la centralización del poder.

En el capítulo VI "El ciclo ritual», el más extenso, hace una detallada descripción del ciclo ritual, religioso y cívico, en Joya de Cerén, siguiendo la antropología simbólica y el análisis de las fases del ritual de Victor Turner, aderezada con las ideas orientadoras de Levi-Strauss en relación con que en los rituales se presentan principios de oposición y complementariedad que relacionan a los diferentes símbolos dentro de un sistema cultural.

Argumenta que la importancia del ritual subyace en que a través de él se expresan los tipos de conciencia social de la comunidad, las cuales identifica como: popular, comunitaria, ciudadana (civitas), oficial y eclesiástica (ecclesia). Encuentra, entonces, tres principios fundamentales del sistema de valoración y normatividad social en Joya de Cerén: glorificación, unidad social y sacrificio. Esta tríada genera una lógica cultural, concluye el autor, de carácter conservador de la cultura local.

Para comentar las conclusiones generales, es necesario regresar a los tópicos que aborda Lara Martínez (2013) en su introducción y que hemos triangulado intensamente a través de mi intervención docente y dirección de trabajos de grado en la Universidad de El Salvador (UES): el entramado teórico-metodológico que da sustento a la investigación y que guían en gran medida la perspectiva metodológica de la antropología que se enseña en la UES. Frente a mi preferencia por el análisis desde la perspectiva de campo social, que tiene sus orígenes en el legado teórico y etnográfico del trabajo de Max Gluckman; Lara mantiene una orientación más etnológica y el principio del estudio de la comunidad como una totalidad sociocultural.

Considero que hablamos de procedimientos analíticos que seleccionan ópticas distintas. El principio de totalidad sociocultural que sigue en este libro, el autor refiere a:

...tres grandes niveles de interpretación: el estudio de la historia local, que permite observar a la comunidad rural en constante transformación [capítulos I y II]; el estudio de la estructura de relaciones sociales, lo que normalmente se conoce como estructura social, que incluye las relaciones económicas, políticas y de ayuda mutua [capítulos III y IV]; y el estudio del sistema de representación simbólica, que nos lleva a desentrañar el sistema de normas y valores que ha sido creado a través de la interacción social [capítulo V] (Lara, 2013, p. 17; énfasis agregado).

http://revistas.ucr.ac.cr/index.php/antropologia 
Mientras que, desde la problemática del poder, la noción de campo social refiere a un análisis de las interacciones sociales de distintos grupos incluyendo las posiciones relacionales que ellos guardan dentro de ellas; es decir, la estructura de relaciones sociales como construcciones sociales producidas en condiciones socio-históricas específicas que incluyen los objetos específicos que se disputan en las relaciones políticas; así como las normas y reglas del sistema de representación simbólica.

El estudiantado generalmente se forma de la representación que el estudio de la comunidad como totalidad sociocultural es idéntico a un sistema cerrado o que refiere al hecho que podemos identificar a la comunidad empíricamente con una entidad territorial claramente delimitada sobre la cual se sobrepone una identidad cultural autocontenida; como si comunidad $\equiv$ territorio $\equiv$ cultura. Este es un error común no solo de los antropólogos(as) en formación; sino de muchos que consideran que en su trabajo sigue fielmente el canon antropológico del trabajo de campo en la comunidad y de aquellos que en las corrientes contemporáneas realizan lo que llaman una antropología comprometida.

El constante contrapunto refiere a una mala lectura de los postulados de Lara (2013), pues él mismo afirma que "el sistema social no es un objeto que podemos observar directamente sobre el terreno", es decir, coincidimos - a pesar de nuestras posiciones teórico-metodológicas distintas- en que la Antropología es una disciplina que exige un alto nivel de abstracción para llegar a explicaciones cada vez más robustas. Resulta, claro está, sumamente complicado transformar aquella representación en la que la comunidad mantiene una relación isomorfa de identidad con un territorio y estos con la cultura; para transitar a la abstracción que se requiere en Antropología para comprender que nuestro aporte al conocimiento de la realidad social está en el análisis de las normas y valores que orientan las interacciones sociales.

Síntesis, esta última, que Lara Martínez realiza en el capítulo VII "Conclusiones generales", donde presenta una visión integral del funcionamiento de la comunidad rural estudiada; mejor dicho, recapitula las interacciones sociales observadas en el presente etnográfico y explica que son orientadas, tanto por las fuerzas estructurales que encuentran raigambre en la historia como por la decisión de los semicampesinos por mantener su nivel de subsistencia y de inversión en las relaciones sociales de solidaridad; decisiones que son reforzadas - hasta el momento del estudio- por las normas y valores que se transmiten a través de un sistema ritual.

Desde luego, el libro aquí reseñado es una muestra de que los métodos de la Antropología, en particular el trabajo de campo etnográfico y la búsqueda de la objetividad científica, a pesar de la proximidad que el antropólogo(a) debe logar con los actores en el campo, son aún necesarios a pesar de este mundo en transformación. Entonces, considero que otro importante aporte del libro se trata de enseñar esos principios a los 
futuros antropólogos(as) que trabajarán, tal como lo señalaba al inicio de este documento, en un mundo de movimiento de poblaciones, mundos sociales multilocales, lealtades desplazadas y circulación global de significados.

Contexto significativo para volver a la pregunta ¿qué es una comunidad? Con esto reitero que esta categoría no está aún del todo discutida y que gran parte de los problemas que guían la investigación antropológica contemporánea se anclan a ella.

Por este motivo, considero que esta obra es la base para dar respuestas a preguntas para futuras investigaciones que nos ayuden a avanzar en nuestras reflexiones metodológicas sobre cómo hacer una etnografía de la comunidad en el contexto de un mundo en el que todos los elementos que observamos son, en cierto modo, poslocales; y en la discusión teórica en relación con cuáles son los principios ordenadores de las nuevas comunidades.

Y aquí estamos en el corazón mismo de la antropología contemporánea. Entender que la comprensión antropológica requiere de esa visión de totalidad en la que el mundo ritual nos explica la forma en que se transmiten las normas y valores que unen a un grupo social, que este no es todo homogéneo, sino un mundo complejo que podemos observar con mayor claridad a través del análisis político y las disputas por los recursos significativos. Aspectos todos ellos que no se desligan de los principios de solidaridad y ayuda que se generan en las redes de relaciones fundamentadas en el grupo doméstico, en un mundo regido por nuevos principios de interacción.

Este es el gran aporte de Joya de Cerén. La dinámica sociocultural de una comunidad semicampesina de El Salvador y el principal motivo por el que invito a su atenta lectura.

Esta es una versión revisada de los comentarios realizados en la presentación del libro que tuvo verificativo el miércoles 23 de octubre de 2013, Centro Cultural de España, San Salvador, El Salvador, C. A. 